\title{
Bile Duct Brush Cytology - Challenges, Limitations and Ancillary Studies
}

\author{
Sangeeta Mantoo* \\ Department of Anatomical Pathology, Singapore General Hospital, Singapore
}

Submission: April 08, 2017; Published: May 09, 2017

*Corresponding authors: Sangeeta Mantoo, Department of Anatomical Pathology, Singapore General Hospital, Singapore, Fax: (65) 62276562;

Email: sangeetamantoo@gmail.com

\begin{abstract}
Brush cytology of the bile duct, pancreatic duct, common bile duct and the ampulla has become an established tool in evaluating obstructive biliary strictures and masses since mid 1970s. Cytology remains the initial choice in determining the precise nature preoperatively, especially because of the unwanted complications that follow the biopsy of these lesions. Most benign strictures are managed by ductal dilatation or stenting while for the malignant strictures Whipple resection or bile duct resection is undertaken when operable. Therefore, confirmation of the benign or malignant nature of the stricture is of prime clinical importance. Recognition of certain key features on cytology can help categorise these cases into suitable definitive categories and thus help the clinicians to better and timely manage patients. The cytology of the biliary tract has a high specificity, but its sensitivity is quite poor. Growing wealth of ancillary tests can be utilised with the indeterminate cytology results to facilitate patient outcome.
\end{abstract}

Keywords: ERCP; Bile duct rush cytology; Bile duct strictures; Ancillary tests

Abbreviations: ERCP: Endoscopic Retrograde Cholangio-Pancreatography; LBC: Liquid Based Cytology; PSC: Primary Sclerosing Cholangitis; BilIN: Biliary Intraepithelial Neoplasia; NC: Nuclear Cytoplasmic; FISH: Fluorescent In Situ Hybridization; NGS: Next Generation Sequencing

\section{Introduction}

The use of Endoscopic Retrograde CholangioPancreatography (ERCP) was first reported in 1968 and since then it has served as an effective technique in evaluation and treatment of pancreatic and biliary diseases. Osnes et al. introduced use of brush with ERCP in mid 1970s, and brush cytology of the bile duct, pancreatic duct, common bile duct and the ampulla has become an established tool in evaluating obstructive biliary strictures and masses since. Clinical management of biliary strictures is a difficult diagnostic problem and cytology remains the initial choice in determining the precise nature of these lesions preoperatively, given that significant complications may arise from biopsy at these sites $[1,2]$. Most benign strictures are managed by ductal dilatation or stenting, while the malignant strictures if operable are treated by Whipple resection or bile duct resection. In patients with unresectable lesions, clinicians may treat with simple stenting or neoadjugant chemo- and radiation therapy to shrink the tumor prior to surgery. Therefore, pre-operative confirmation of the benign or malignant nature of the stricture is of great clinical importance.

Brushings in comparison to bile sampling yield cellular specimens and have a very high specificity ranging from $87 \%$ -
$100 \%$. However, due to technical, biological and other problems the sensitivity of brush cytology is quite poor and is reported as $30 \%-60 \%$ in most published studies [2,3]. Factors like the toxic nature of bile, tumour desmoplasia, sub mucosal location of mass, stones, stents, parasites, ulceration and inflammatory conditions may contribute to the low sensitivity, in addition to sampling errors. Artefacts may occur due to smearing, air-drying and obscuring blood or inflammatory cells in the conventional smears. Fortunately, these have been significantly reduced by the use of liquid based cytology (LBC) preparations [4,5].

Whilst the cytologic diagnosis of positive for malignancy is of great value in directing patient management, a negative diagnosis may not be of help to the clinician. Another issue is the use of indeterminate diagnostic terminologies (like atypical and suspicious) especially in the context of cytologic atypia [6]. This is further complicated by the fact that atypia can be marked in inflammatory conditions such as Primary Sclerosing Cholangitis (PSC), stents, stones and ulceration, potentially mimicking malignancy. Therefore, the threshold for malignant diagnosis is generally high. While these challenges are real, role of cytopathologists is to help the clinicians by reaching a definitive diagnosis in most cases, in concert with other available findings. 


\section{Discussion}

In 2015, the Papanicolaou Society of Cytology published diagnostic categories for pancreatobiliary lesions in an attempt to better stratify the risk of malignancy and incorporate biliary intraepithelial neoplasia (BilIN) into the cytologic diagnoses. These categories include Non-diagnostic, Negative, Atypical, Neoplastic, Suspicious and Malignant [7]. The documented risk of malignancy is $44-62 \%$ in the Atypical category, $74 \%$ in the Suspicious category and $100 \%$ in the Malignant category. As expected, both the Atypical and Suspicious categories have high inter- and intra-observer variability $[2,6]$.

\section{Cytological features}

On cytologic examination, a "Benign" brushing shows cohesive clusters/sheets of cells arranged in a regular honeycomb pattern, with retained polarity, displaying cells with a low nuclear cytoplasmic (NC) ratio, smooth nuclear membranes, an even chromatin pattern, small conspicuous nucleoli, and no necrosis or mitoses (Figure 1).
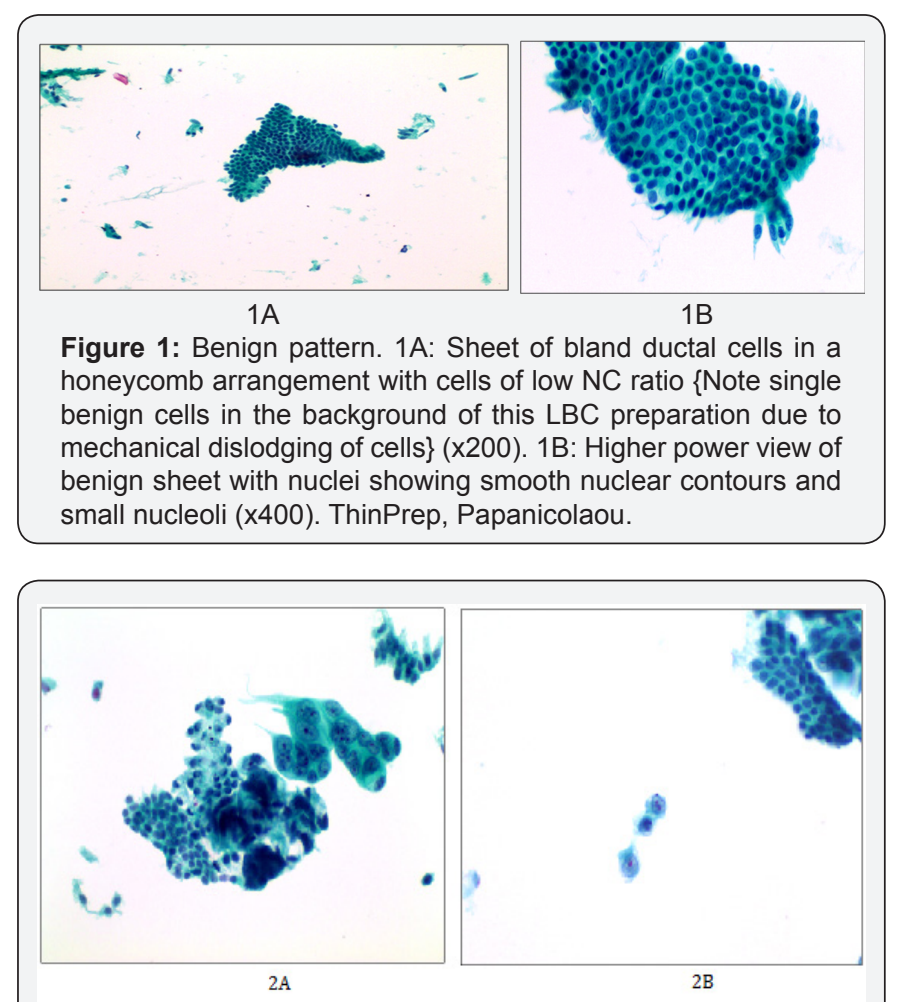

Figure 2: Malignant pattern. 2A: Two distinct populations of cells in this figure with cluster on the left appearing clearly benign and cluster on the right showing markedly atypical cells with loss of honeycomb pattern and anisonucleosis of 4 fold variation within a cluster (x400). 2B: Notice presence of single abnormal cells, one of the strong indicators of malignancy $(x 400)$. ThinPrep, Papanicolaou.

Many studies have utilized linear regression analyses to determine which criteria are most accurate in separating benign from malignant. While a constellation of features would support a "Malignant" cytological diagnosis, several criteria are of particular significance. These include nuclear moulding, chromatin clumping, high NC ratios, loss of honeycomb pattern, more than fourfold variation in nuclear size within a cluster, cellin-cell appearance as well as the presence of single abnormal cells (Figure 2). Of great help is the presence of two distinct cell populations, one of clearly benign and the other obviously atypical features, especially if the differential diagnosis is marked reactive atypia in the clinical context of cholelithiasis, Primary Sclerosing Cholangitis (PSC) etc, in which one should see a gradation of changes rather than two distinct populations.

Smears falling into intermediate category of "Atypical" should show nuclear, cytoplasmic or architectural features that are not consistent with normal or reactive cellular changes but are insufficient for a Neoplastic or Suspicious diagnosis [6,7]. Follow-up evaluation is warranted. Histology in this category usually shows reactive atypia and low grade dysplastic (BilIN 1) lesions; although a significant proportion may have malignant outcomes [7]. In the Atypical category, anisonucleosis within a cluster generally amounts to up to threefold variation, even though nuclear enlargement and prominent nucleoli can be seen in marked reactive atypia in the context of stones, stents, PSC etc.

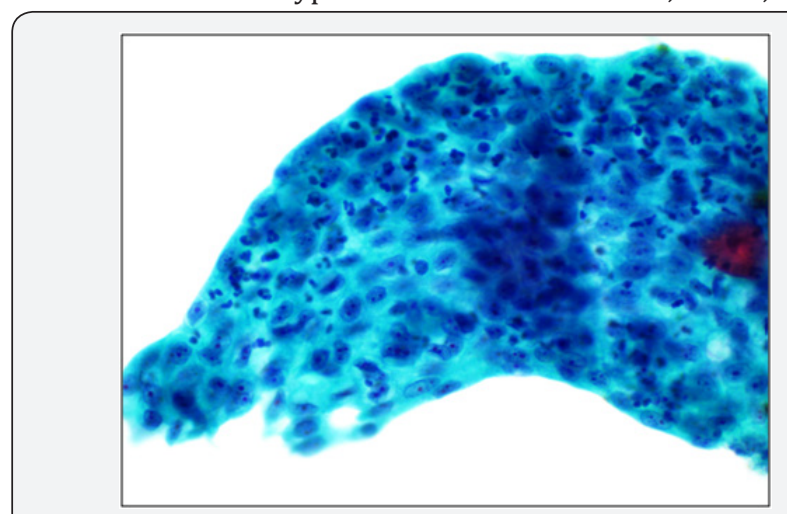

Figure 3: Atypical pattern, reactive atypia. Sheet of ductal cells with mild overlapping, cells with enlarged nuclei, but maintained NC ratios, prominent nucleoli, and presence of neutrophils. (x400). ThinPrep, Papanicolaou.

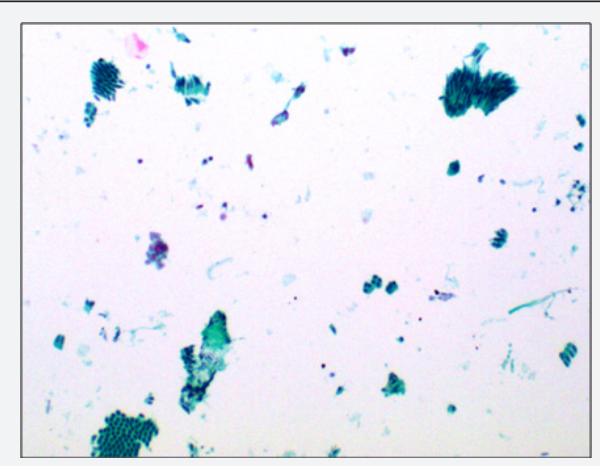

Figure 4: Atypical pattern, BillN 1. Two distinct populations of cells in this figure with cluster on the bottom left appearing clearly benign and cluster on the top right showing cells with palisaded appearance, elongated hyperchromatic nuclei with low NC ratios. Not showing much anisonucleosis (x100). ThinPrep, Papanicolaou.

Low NC ratios, the presence of inflammatory cells and gradation of cellular changes are helpful features to prevent 
overcall in atypical reactive cases (Figure 3), while the presence of nuclear stratification with hyperchromasia and elongation in cells of low NC ratio favour BilIN 1 (Figure 4) [8,9]. In addition, BilIN 1 has two distinct populations of cells. Because 'Atypical' is an indeterminate category, it should be used sparingly.

The "Suspicious" for malignancy category includes lesions with greater dysmorphology than seen in Atypical category, but with findings that are qualitatively and/or quantitatively insufficient for a conclusive diagnosis of malignancy. Histologic follow-up of the lesions assigned to this category demonstrate high-grade dysplasia (BilIN 2\&3) as well as carcinomas of the bile duct. Thankfully, distinction of high grade dysplasia from invasive adenocarcinoma is typically not necessary on cytology.

\section{Ancillary testing}

Because of the low sensitivity of biliary brushing cytology, a number of ancillary techniques testing methods have been utilized including Digital Imaging Analyses (DIA), immunolabelling (with CD10, IMP3, MUC4 and SMAD4), mutational analyses for Kras, p53, loss of heterozygosity and fluorescent in situ hybridization (FISH) analysis. FISH can be performed on the biliary brushing specimen, including LBC preparations, and has reportedly higher sensitivity than cytology alone. It utilizes commercial UroVysion FISH probe kit targeting pericentromeric regions of chromosomes 3, 7, and 17 as well as chromosomal band 9p21. Studies have shown that the sensitivity of FISH is approximately $90 \%$ with a related specificity of $94 \%$. Its positive predictive value is $98 \%$ and negative predictive value is $75 \%$. The method can be performed on liquid-based preparations as well as cell block materials [2]. For better distinction between reactive atypia and malignancy, a targeted FISH analysis of the atypical cells of interest, through use of automated relocation, allows for a more precise evaluation, even in paucicellular specimens [5]. Dudley et al. [9] recently compared Next Generation Sequencing (NGS) on biliary cytology specimens to cytology. When NGS and cytology were combined, NGS increased the sensitivity of cancer detection to $85 \%$, whereas UroVysion only increased sensitivity to $76 \%[10]$.

\section{Conclusion}

In conclusion, the pertinent cytologic features for differentiating benign from malignant have been summarised and the limitations and challenges faced in biliary cytology as well as ancillary help available have been discussed. It isparticularly important that the diagnostic workup of biliary strictures or mass lesions is based on a multidisciplinary team approach. Clinical findings, imaging and, endoscopic findings and cytologic diagnoses must all be reviewed in multidisciplinary meetings to select the appropriate management and patient follow-up procedures.

\section{References}

1. Winifred Gray, Gabrijela Kocjan (2010) Chapter 9 In: Gall bladder and extrahepatic bile ducts. Diagnostic Cytopathology. (3rd edn), Churchill Livingstone Elsevier, USA.

2. Layfield L, Ehya H, Filler AC, Hruban RH, Jhala N, et al. (2014) Utilization of Ancillary studies in the cytologic diagnosis of biliary and pancreatic lesions: the Papanicolaou society of cytology guidelines of pancreatobiliary cytology. Diagn Cytopath 42(4): 351-362.

3. Bardales RH, Stanley MW, Simpson DD, Baker SJ, Steele CT, et al. (1998) Diagnostic value of brush cytology in the diagnosis of duodenal, biliary, and ampullary neoplasms. Am J Clin Pathol 109(5): 540-548.

4. Volmar KE, Vollmer RT, Routbort MJ, Creager AJ (2006) Pancreatic and bile duct brushing cytology in 1000 cases: review of findings and comparison of preparation methods. Cancer 108(4): 231-238.

5. Elhosseiny A, Bakkar R, Zenali M (2014) Cytology of the Biliary Tree. Ann Clin Pathol 2(2): 1015.

6. Chadwick BE, Layfield LJ, Witt BL, Schmidt RL, Cox RN, et al. (2014) Significance of atypia in pancreatic and bile duct brushings: followup analysis of the categories atypical and suspicious for malignancy. Diagn Cytopathol 42(4): 285-291.

7. Pitman MB, Layfield LJ (2015) The Papanicolaou Society of Cytopathology System for Reporting Pancreaticobiliary Cytology. Springer.

8. Stewart CJ, Mills PR, Carter R, O'Donohue J, Fullarton G, Imrie CW, et al. (2001) Brush cytology in the assessment of pancreatico-biliary strictures: a review of 406 cases. J Clin Pathol 54(6): 449-455.

9. Veronezi-Gurwell A, Wittchow RJ, Bottles K, Cohen MB (1996) Cytologic features of villous adenoma of the ampullary region. Diagn Cytopathol 14(2): 145-149.

10. Dudley JC, Zheng Z, McDonald T, Le LP, Dias-Santagata D, et al. (2016) Next-generation sequencing and fluorescence in situ hybridization have comparable performance characteristics in the analysis of pancreaticobiliary brushings for malignancy. J Mol Diagn 18(1): 124130.

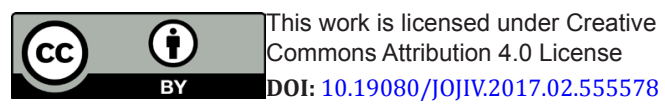

\begin{tabular}{|l|}
\hline \multicolumn{1}{|c|}{ Your next submission with Juniper Publishers } \\
will reach you the below assets \\
- Quality Editorial service \\
- Swift Peer Review \\
- Reprints availability \\
- E-prints Service \\
- Manuscript Podcast for convenient understanding \\
- Global attainment for your research \\
- Manuscript accessibility in different formats \\
( Pdf, E-pub, Full Text, Audio) \\
- Unceasing customer service \\
Track the below URL for one-step submission \\
https://juniperpublishers.com/online-submission.php \\
\hline
\end{tabular}

